
JACEK SZKUTNIK ${ }^{1}$, PIOTR MAJCHER ${ }^{2}$, JOLANTA SZYMAŃSKA ${ }^{4}$

\title{
Use of common stimulants and awake bruxism - a survey study
}

\begin{abstract}
Introduction. Bruxism, the most detrimental parafunctional activity of the masticatory system can cause various temporomandibular joint disorders, as well as masticatory muscle disorders. It is important to identify factors aggravating bruxism, which can be easily eliminated and ease control of the disorder.

Aim. The aim of the study was to analyze the association between the use of common stimulants - nicotine, caffeine and selfreports of awake bruxism.

Material and methods. 113 dental students (83 females, 30 males) aged 21-29 were examined. In order to diagnose awake bruxism subjects were asked questions from the Oral Behaviors Checklist. Patients were also asked about daily/weekly frequency of cigarette smoking and coffee as well as caffeine-containing beverages consumption.

Results. Cigarette smoking was positively associated with self-reported awake bruxism. There was no link found between caffeine consumption and parafunctional activities.

Conclusion. Cigarette smoking, but not caffeine consumption, may be a risk factor for awake bruxism. However, this association should be further assessed in the presence of confounding factors, such as psychological distress.
\end{abstract}

Keywords: bruxism, tobacco smoking, caffeine.

DOI: $10.1515 /$ pjph-2016-0027

\section{INTRODUCTION}

Temporomandibular disorders (TMD) are common musculoskeletal conditions, attributed to temporomandibular joints (TMJ) and muscles of mastication, characterized by the presence of persistent orofacial pain. It is estimated that painful TMD is the third, after common headache and back pain, most prevalent condition associated with chronic pain [1]. Persistence of TMD often results in psychological distress, social impairment, reduced quality of life and working capacity [2]. Moreover, high healthcare utilization of chronic TMD patients generates enormous costs. It is estimated that total cost of TMD treatment in the United States of America exceeds US\$ 5000 in more than half of the cases [3]. Therefore, costeffective treatments of TMD are likely to be indicated.

Some risk factors for TMD pain were identified, including genetic, psychosocial, demographic and neurophysiological factors, though the exact etiology of TMD remains unknown [4]. Besides the above mentioned factors, parafunctional activity (jaw activity not related to physiological function) was also found to be a significant risk factor for painful TMD [5]. The most detrimental parafunctional activity of the masticatory system is bruxism, which is defined as a repetitive jaw-muscle activity, characterized by clenching or grinding of the teeth and/or by bracing or thrusting of the mandible.
Two distinct circadian manifestations of bruxism (sleep and awake) are distinguished [6]. Awake bruxism is defined as the clenching of teeth and jaws during wakefulness, in comparison to sleep bruxism, which characterized by unconscious clenching or grinding of teeth during sleep [7]. Prevalence of bruxism in general population is not accurately estimated and varies from $15 \%$ to $36 \%$ across the studies, depending on the diagnostic method [8-11]. It is worth noting that bruxism is significantly more prevalent in patients with temporomandibular disorders in comparison to healthy subjects [12,13].

Recently, it was shown that self-reported awake bruxism was associated with TMD pain complaints $[14,15]$. This observation can be supported by the results of experimental studies, which demonstrated that clenching can aggravate masseter muscle pain in patients with TMD [16]. Moreover, individuals with masticatory muscle pain were shown to have an increased frequency of daytime teeth clenching episodes [17].

It is now known that psychological distress is associated with the prevalence of awake bruxism, while despite earlier suspicions, no relationship between emotional stress and sleep bruxism was found [18]. Risk factors for sleep bruxism were investigated in many studies, it was found that alcohol consumption, cigarette smoking and certain drugs can increase levels of bruxism [19-21]. Caffeine - the most widely used neurostimulant in the word, and cigarette smoking - exceeding

\footnotetext{
${ }^{1}$ Department of Functional Masticatory Disorders, Medical University of Lublin, Poland

${ }^{2}$ Chair and Department of Rehabilitation, Physiotherapy and Balneotherapy, Medical University of Lublin, Poland

${ }^{3}$ Medial Students' Research Association, Department of Functional Masticatory Disorders, Medical University of Lublin, Poland

${ }^{4}$ Chair and Department of Paedodontics, Medical University of Lublin, Poland
} 
$30 \%$ prevalence worldwide, pose a significant public health problem $[22,23]$. The evidence on the association between these factors and awake bruxism are lacking. Thus, it is important to identify factors aggravating awake bruxism that can be relatively easily eliminated.

\section{AIM}

The aim of our study was to analyze the association between the use of common stimulants - nicotine and caffeine, and self-reports of awake bruxism.

\section{MATERIAL AND METHODS}

The participants in this study comprised 113 dental students (83 females, 30 males), aged 21-29. In order to assess the frequency of awake bruxism subjects were asked to answer selected questions from the Oral Behaviors Checklist, a 21-item questionnaire regarding the activities of the masticatory system [10].

The following questions were used:

1. Do you grind teeth together during waking hours?

2. Do you clench teeth together during waking hours?

3. Do you press, touch, or hold teeth together other than while eating (that is, contact between upper and lower teeth)?

4. Do you hold, tighten, or tense muscles without clenching or bringing teeth together?

The questionnaire employed five response options in Likerttype scale $(0$ - never, 1 - very rarely, 2 - rarely, 3 - often, 4 very often) [24].

Participants were also asked, using open questions, about weekly frequency of cigarette smoking and consumption of coffee and caffeine containing beverages.

The frequency of cigarette smoking was classified in the following categories: 0 - never, 1 - rarely (no more than 4 per day), 2 - often (5-20 per day).

TABLE 1. Relationship between cigarette smoking and selected oral behaviors.

\begin{tabular}{|c|c|c|c|c|c|}
\hline $\begin{array}{c}\text { Type of oral } \\
\text { behavior }\end{array}$ & $\begin{array}{l}\text { Frequency } \\
\text { of cigarette } \\
\text { smoking }\end{array}$ & $\mathrm{n}$ & $\begin{array}{c}\text { Mean } \\
\text { rank }\end{array}$ & H-Value & p-Value \\
\hline \multirow{4}{*}{$\begin{array}{l}\text { 1. Grinding teeth } \\
\text { together during } \\
\text { waking hours }\end{array}$} & Never & 92 & 53.95 & \multirow{4}{*}{8.555} & \multirow{4}{*}{$<0.05^{*}$} \\
\hline & Rarely & 16 & 71.47 & & \\
\hline & Often & 5 & 66.80 & & \\
\hline & Total & 113 & & & \\
\hline \multirow{4}{*}{$\begin{array}{l}\text { 2. Clenching teeth } \\
\text { together during } \\
\text { waking hours }\end{array}$} & Never & 92 & 53.26 & \multirow{4}{*}{8.473} & \multirow{4}{*}{$<0.05^{*}$} \\
\hline & Rarely & 16 & 78.06 & & \\
\hline & Often & 5 & 58.40 & & \\
\hline & Total & 113 & & & \\
\hline \multirow{4}{*}{$\begin{array}{l}\text { 3. Pressing, touching, } \\
\text { or holding teeth } \\
\text { together other than } \\
\text { while eating }\end{array}$} & Never & 92 & 53.17 & \multirow{4}{*}{8.214} & \multirow{4}{*}{$<0.05^{*}$} \\
\hline & Rarely & 16 & 77.94 & & \\
\hline & Often & 5 & 60.40 & & \\
\hline & Total & 113 & & & \\
\hline \multirow{4}{*}{$\begin{array}{l}\text { 4. Holding, tightening, } \\
\text { or tensing muscles } \\
\text { without clenching } \\
\text { or bringing teeth } \\
\text { together }\end{array}$} & Never & 92 & 57.08 & \multirow{4}{*}{0.023} & \multirow{4}{*}{$>0.05$} \\
\hline & Rarely & 16 & 56.19 & & \\
\hline & Often & 5 & 58.20 & & \\
\hline & Total & 113 & & & \\
\hline
\end{tabular}

$*$ significant differences $(\mathrm{p}<0.05)$
The frequency of coffee consumption, as well as caffeine containing beverages, was classified in the following categories: 0 - never, 1 - rarely (no more than 3 per week), 2 - often (1-4 per day).

The relationship between cigarette smoking and caffeine consumption frequency, and the frequency of selected oral behaviors were evaluated using rank-based nonparametric Kruskal-Wallis $\mathrm{H}$ test. The level of significance was set at $\mathrm{p}<0.05$. Data were analyzed using IBM SPSS Statistics Version 20 software.

\section{RESULTS}

The frequency of cigarette smoking was significantly associated with the frequency of three oral behaviors $-1,2$ and 3 (Table 1). Consumption of coffee and caffeine containing beverages was not related to the frequency of investigated oral behaviors (Table 2, 3).

\section{DISCUSSION}

The association between the use of stimulants - nicotine and caffeine and self-reports of awake bruxism insufficiently investigated. The knowledge of these factors could have the practical importance of controlling awake bruxism, which could be beneficial in the management of TMD.

Caffeine avoidance is recommended to TMD patients in a self-care program. The International Association for The Study of Pain, where it is argued that caffeine may increase jaw tension contributing to jaw pain [25]. However, we were not able to identify literature supporting the opinion that caffeine may increase jaw muscles' activity. Moreover, the results from our study did not reveal association between caffeine intake and frequency of oral behaviors typical for awake bruxism.

Current tobacco use was associated with more pain interference in subjects with TMD [26]. A study by Sanders et al.

TABLE 2. Relationship between coffee consumption and selected oral behaviors.

\begin{tabular}{|c|c|c|c|c|c|}
\hline $\begin{array}{c}\text { Type of oral } \\
\text { behavior }\end{array}$ & $\begin{array}{l}\text { Frequency } \\
\text { of caffeine } \\
\text { consumption }\end{array}$ & $\mathrm{n}$ & $\begin{array}{c}\text { Mean } \\
\text { rank }\end{array}$ & H-Value & p-Value \\
\hline \multirow{4}{*}{$\begin{array}{l}\text { 1. Grinding teeth } \\
\text { together during } \\
\text { waking hours }\end{array}$} & Never & 26 & 53.25 & \multirow{4}{*}{1.736} & \multirow{4}{*}{$>0.05$} \\
\hline & Rarely & 66 & 59.44 & & \\
\hline & Often & 21 & 53.98 & & \\
\hline & Total & 113 & & & \\
\hline \multirow{4}{*}{$\begin{array}{l}\text { 2. Clenching teeth } \\
\text { together during } \\
\text { waking hours }\end{array}$} & Never & 26 & 49.58 & \multirow{4}{*}{3.131} & \multirow{4}{*}{$>0.05$} \\
\hline & Rarely & 66 & 61.35 & & \\
\hline & Often & 21 & 52.52 & & \\
\hline & Total & 113 & & & \\
\hline \multirow{4}{*}{$\begin{array}{l}\text { 3. Pressing, touching, } \\
\text { or holding teeth } \\
\text { together other } \\
\text { than while eating }\end{array}$} & Never & 26 & 47.38 & \multirow{4}{*}{5.072} & \multirow{4}{*}{$>0.05$} \\
\hline & Rarely & 66 & 62.63 & & \\
\hline & Often & 21 & 51.21 & & \\
\hline & Total & 113 & & & \\
\hline \multirow{4}{*}{$\begin{array}{l}\text { 4. Holding, tighten- } \\
\text { ing, or tensing } \\
\text { muscles without } \\
\text { clenching or bringing } \\
\text { teeth together }\end{array}$} & Never & 26 & 50.15 & \multirow{4}{*}{4.367} & \multirow{4}{*}{$>0.05$} \\
\hline & Rarely & 66 & 61.70 & & \\
\hline & Often & 21 & 50.71 & & \\
\hline & Total & 113 & & & \\
\hline
\end{tabular}


TABLE 3. Relationship between consumption of caffeine containing beverages and selected oral behaviors.

\begin{tabular}{|c|c|c|c|c|c|}
\hline $\begin{array}{c}\text { Type of oral } \\
\text { behavior }\end{array}$ & $\begin{array}{l}\text { Frequency } \\
\text { of caffeine } \\
\text { containing } \\
\text { beverages } \\
\text { consumption }\end{array}$ & $\mathrm{n}$ & $\begin{array}{c}\text { Mean } \\
\text { rank }\end{array}$ & H-Value & p-Value \\
\hline \multirow{4}{*}{$\begin{array}{l}\text { 1. Grinding teeth } \\
\text { together during } \\
\text { waking hours }\end{array}$} & Never & 96 & 57.99 & \multirow{4}{*}{1.534} & \multirow{4}{*}{$>0.05$} \\
\hline & Rarely & 13 & 53.38 & & \\
\hline & Often & 4 & 45.00 & & \\
\hline & Total & 113 & & & \\
\hline \multirow{4}{*}{$\begin{array}{l}\text { 2. Clenching teeth } \\
\text { together during } \\
\text { waking hours }\end{array}$} & Never & 96 & 55.54 & \multirow{4}{*}{1.387} & \multirow{4}{*}{$>0.05$} \\
\hline & Rarely & 13 & 65.62 & & \\
\hline & Often & 4 & 64.13 & & \\
\hline & Total & 113 & & & \\
\hline \multirow{4}{*}{$\begin{array}{l}\text { 3. Pressing, touching, } \\
\text { or holding teeth } \\
\text { together other than } \\
\text { while eating }\end{array}$} & Never & 96 & 57.47 & \multirow{4}{*}{0.300} & \multirow{4}{*}{$>0.05$} \\
\hline & Rarely & 13 & 52.62 & & \\
\hline & Often & 4 & 60.00 & & \\
\hline & Total & 113 & & & \\
\hline \multirow{4}{*}{$\begin{array}{l}\text { 4. Holding, tighten- } \\
\text { ing, or tensing } \\
\text { muscles without } \\
\text { clenching or bringing } \\
\text { teeth together }\end{array}$} & Never & 96 & 56.05 & \multirow{4}{*}{3.073} & \multirow{4}{*}{$>0.05$} \\
\hline & Rarely & 13 & 56.50 & & \\
\hline & Often & 4 & 81.38 & & \\
\hline & Total & 113 & & & \\
\hline
\end{tabular}

showed that exposure to tobacco can be considered a risk factor for TMD. Moreover, smokers were twice as likely as nonsmokers to perceive high psychological distress [27]. Melis et al. findings suggested that control of smoking habits should be considered during TMD patients' treatment. [28].

In contrast to our results, Quadri et al. reported that there was no significant association between awake bruxism and tobacco smoking among university students from Saudi Arabia [29]. Discrepancies in the results may be explained by different compositions of study groups. The study by Quadri et al. comprised more men than women $(71 \%$ men), while in our study women comprised majority of the participants $(73 \%$ women) [29]. Women report more intense, more numerous, and more frequent bodily symptoms than men [30]. Therefore, it is possible that women were more likely to report the presence of oral behaviors than men did.

It is worth noting that Quadri et al. found an association between awake bruxism and psychological stress reported by the participants [29]. Psychological distress, which is positively correlated with the presence of awake bruxism, was not evaluated in our study [18]. Lack of psychological distress assessment could create a risk of bias. Hence, the above mentioned factor can be a potential confounder. Studies show that anxiety is associated with increased tobacco use, so it is possible that increased frequency of cigarette smoking was accompanied by psychological distress [31]. Therefore, it is possible that the correlation between cigarette smoking and awake bruxism was spurious, and resulted from the presence of psychological factors related to cigarette smoking.

It is interesting that Quadri et al. found that awake bruxism was associated with khat (Catha edulis) chewing [29]. Saudi Arabia is among the countries with the highest population of khat chewers, which is rare in Europe [32]. Hence, khat chewing can be interpreted as a substitute for cigarettes in stressful situations. In this case, the observed relationship between khat and awake bruxism may be spurious as well, and in fact be a result of psychological distress. Damena et al., findings suggest that persons who use khat suffer from higher rates of mental distress [33].

Demonstration of cause-effect relationship between nicotine intake and daytime parafunctions is important due to possible use of smoking cessation in management of TMD pain, thus should be investigated in further studies.

\section{CONCLUSIONS}

Cigarette smoking, but not caffeine consumption, may be a risk factor for awake bruxism. However, this association should be further assessed in the presence of confounding factors, such as psychological distress.

\section{REFERENCES}

1. Dworkin SF. The OPPERA Study: Act One. J Pain. 2011;12:1-3.

2. Cioffi I, Perrotta S, Ammendola L, et al. Social impairment of individuals suffering from different types of chronic orofacial pain. Prog Orthod. 2014;15:27.

3. White BA, Williams LA, Leben JR. Health care utilization and cost among health maintenance organization members with temporomandibular disorders. J Orofac Pain. 2001;15:158-69.

4. Slade GD, Fillingim RB, Sanders AE, et al. Summary of findings from the OPPERA prospective cohort study of incidence of first-onset temporomandibular disorder: implications and future directions. J Pain Off J Am Pain Soc. 2013;14:116-24

5. Poveda Roda R, Bagan JV, Díaz Fernández JM, et al. Review of temporomandibular joint pathology. Part I: classification, epidemiology and risk factors. Med Oral Patol Oral Cir Bucal. 2007;12:E292-8.

6. Lobbezoo F, Ahlberg J, Glaros AG, et al. Bruxism defined and graded: an international consensus. J Oral Rehabil. 2013;40:2-4.

7. Lavigne GJ, Khoury S, Abe S, et al. Bruxism physiology and pathology: an overview for clinicians. J Oral Rehabil. 2008;35:476-94.

8. Machado E, Dal-Fabbro C, Cunali PA, et al. Prevalence of sleep bruxism in children: a systematic review. Dent Press J Orthod. 2014;19:54-61.

9. Nekora-Azak A, Yengin E, Evlioglu G, et al. Prevalence of bruxism awareness in Istanbul, Turkey. Cranio J Craniomandib Pract. 2010;28:122-7.

10. Van Selms MKA, Visscher CM, Naeije M, et al. Bruxism and associated factors among Dutch adolescents. Community Dent Oral Epidemiol. 2013;41:353-63.

11. Serra-Negra JM, Scarpelli AC, Tirsa-Costa D, et al. Sleep bruxism, awake bruxism and sleep quality among Brazilian dental students: a cross-sectional study. Braz Dent J. 2014;25:241-7.

12. Kalamir A, Pollard H, Vitiello AL, et al. TMD and the problem of bruxism. A review. J Bodyw Mov Ther. 2007;11:183-93.

13. Manfredini D, Cantini E, Romagnoli M, et al. Prevalence of bruxism in patients with different research diagnostic criteria for temporomandibular disorders (RDC/TMD) diagnoses. Cranio J Craniomandib Pract. 2003;21:279-85.

14. Berger M, Szalewski L, Szkutnik J, et al. Different association between specific manifestations of bruxism and temporomandibular disorder pain. Neurol Neurochir Pol. DOI: 10.1016/j.pjnns.2016.08.008

15. Sierwald I, John MT, Schierz O, et al. Association of temporomandibular disorder pain with awake and sleep bruxism in adults. J Orofac Orthop Fortschritte Kieferorthopädie. 2015;76:305-17

16. Dawson A, Ghafouri B, Gerdle B, et al. Effects of experimental tooth clenching on pain and intramuscular release of 5-HT and glutamate in patients with myofascial TMD. Clin J Pain. 2015;31:740-9.

17. Cioffi I, Landino D, Donnarumma V, et al. Frequency of daytime tooth clenching episodes in individuals affected by masticatory muscle pain and pain-free controls during standardized ability tasks. Clin Oral Investig. 2016. DOI: $10.1007 / \mathrm{s} 00784-016-1870-8$

18. Manfredini D, Lobbezoo F. Role of psychosocial factors in the etiology of bruxism. J Orofac Pain. 2009;23:153-66.

19. Ohayon MM, Li KK, Guilleminault C. Risk factors for sleep bruxism in the general population. Chest. 2001;119:53-61.

20. Rintakoski $\mathrm{K}$, Ahlberg J, Hublin C, et al. Bruxism is associated with nicotine dependence: a nationwide Finnish twin cohort study. Nicotine Tob Res. 2010;12:1254-60 
21. Winocur E, Gavish A, Voikovitch M, et al. Drugs and bruxism: a critical review. J Orofac Pain. 2003;17:99-111.

22. Addicott MA, Yang LL, Peiffer AM, et al. The effect of daily caffeine use on cerebral blood flow: how much caffeine can we tolerate? Hum Brain Mapp. 2009;30:3102-14

23. Hammond SK. Global patterns of nicotine and tobacco consumption. Handb Exp Pharmacol. 2009;192:3-28.

24. Hartley J. Some thoughts on Likert-type scales. Int J Clin Health Psychol. 2014;14:83-6.

25. Fricton J R. Temporomandibular muscle and joint disorders. Pain Clin Updat. $2004 ; 12(2)$.

26. Weingarten TN, Iverson BC, Shi Y, et al. Impact of tobacco use on the symptoms of painful temporomandibular joint disorders. Pain. 2009;147:67-71.

27. Sanders AE, Slade GD, Maixner W, et al. Excess risk of temporomandibular disorder associated with cigarette smoking in young adults. J Pain Off J Am Pain Soc. 2012;13:21-31
28. Melis M, Lobo SL, Ceneviz C, et al. Effect of cigarette smoking on pain intensity of TMD patients: a pilot study. Cranio J Craniomandib Pract. 2010;28:187-92.

29. Quadri MFA, Mahnashi A, Al Almutahhir A, et al. Association of awake bruxism with khat, coffee, tobacco, and stress among Jazan university students. Int J Dent. 2015.

30. Barsky AJ, Peekna HM, Borus JF. Somatic symptom reporting in women and men. J Gen Intern Med. 2001;16:266-75.

31. Moylan S, Jacka FN, Pasco JA, et al. How cigarette smoking may increase the risk of anxiety symptoms and anxiety disorders: a critical review of biological pathways. Brain Behav. 2013;3:302-26.

32. Kassim S, Farsalinos KE. E-cigarette as a harm reduction approach among tobacco smoking khat chewers: a promising bullet of multiple gains. Int J Environ Res Public Health. 2016;13:240.

33. Damena T, Mossie A, Tesfaye M. Khat chewing and mental distress: a community based study, in Jimma city, southwestern Ethiopia. Ethiop J Health Sci. 2011;21:37-45.

\section{Corresponding author}

Marcin Berger

Department of Functional Masticatory Disorders

Karmelicka 7 Street, 20-081 Lublin, Poland

tel./fax: +48 81 528-79-30

E-mail: marcin.berger@umlub.pl 